\title{
Mídia e diversidade cultural : a representação de grupos minoritários na cinematografia canadense
}

\author{
Media and cultural diversity: the representation of minority groups \\ in Canadian cinema
}

\author{
MARIA LUIZA MARTINS DE MENDONÇA \\ Doutora em comunicação e Professora na Faculdade de Comunicação e Biblioteconomia da Universidade \\ Federal de Goiás \\ E-mail:mluisamendonca@gmail.com
}

\section{Resumo}

Este trabalho é parte de uma pesquisa mais extensa que tem por objetivo contribuir para uma melhor compreensão do papel que a presença da diversidade e da diferença nas produções midiáticas pode trazer para os processos de enriquecimento cultural e de democratização das relações sociais. Parte-se do princípio que nas sociedades contemporâneas, em que a lógica do espetáculo se estende para a esfera das relações sociais, a visibilidade midiática implica alguma forma de reconhecimento e de legitimação das diversidades.

Palavras-chave: diversidade, representação, audiovisual, Canadá

Meios de comunicação e grupos minoritários

Estas reflexões, resultantes de uma pesquisa mais extensa, têm como ponto de partida a percepção das produções midiáticas como processos complexos cuja incidência sobre o público vai além da recepção imediata e que atuam como um dos construtores culturais mais importantes da sociedade contemporânea.

Em termos teóricos importa reconhecer que esfera da produção cultural é, em todas as sociedades, aquela em que se realizam o aprendizado e a aquisição de sentidos das relações sociais, das formas de sociabilidade e se constroem visões de mundo. Sua diversidade comporta diferentes maneiras de apreender, avaliar, sedimentar ou transformar as diversas relações que indivíduos e grupos estabelecem entre si nos planos social, econômico, político e religioso. Constitui-se, também, em núcleo gerador de identidade para indivíduos e grupos à medida que oferece modelos com os quais os indivíduos se reconhecem e com os quais se identificam. De forma semelhante, os significados atribuídos aos diferentes grupos sociais são indicativos dos lugares que ocupam no conjunto das representações sociais, dos valores que lhes são atribuídos e também das distintas maneiras de percebê-los, representá-los e de construir concepções a seu respeito. Em termos empíricos é indiscutível a contribuição dos conteúdos midiáticos para a consolidação de valores, para a transmissão de matrizes culturais e para construção de subjetividades em todas as suas implicações: da formação do "gosto pessoal", passando pelas preferências, escolhas, possibilidades e impossibilidades de realização pessoal até as aspirações e ao dever-ser.

É nessa esfera que circulam os diferentes discursos que vão construir subjetividades e onde os indivíduos podem tomar consciência 
de suas reais condições de vida; por isso mesmo, é o campo no qual se desenrola parte de uma luta política, fruto de um processo cultural e histórico para a fixação dos sentidos em uma dada sociedade. Construídas de forma particular em cada tempo e lugar essas subjetividades estão vinculadas às condições de produção da existência, tanto no aspecto material quanto imaterial, este último visto como espaço privilegiado que abriga as tradições, a memória, os valores sociais. A subjetividade não é, portanto, centrada no indivíduo; é um processo social em que estão presentes, além das falas oficiais, hegemônicas, os espaços independentes de articulação e de circulação de discursos dissidentes ou alternativos.

Essas características fazem com que as análises das produções culturais não possam ser dissociadas das relações de poder existentes nas sociedades, poder que não se verifica apenas no sentido político estrito do termo, mas que se estende às relações entre classes, de gênero, étnicas e outras. Nesse sentido, o referencial proposto pretende dialogar com as definições de poder simbólico construídas por Bourdieu (2001, p.15), concebido como o "poder de constituir o dado pela enunciação, de fazer e fazer crer, de confirmar ou de transformar a visão de mundo e, deste modo, a ação sobre o mundo, portantoo mundo.

Nessa perspectiva, é legítimo avaliar tanto os conteúdos de certos produtos da indústria cultural do ponto de vista de sua articulação com os poderes hegemônicos, sua capacidade de produção e reprodução de sentidos e, dialeticamente, as possibilidades de produção e circulação de narrativas contrahegemônicas e de sua contribuição para a democratização das relações sociais, em sentido amplo. Pode-se, também, considerar as cinematografias nacionais como sendo, também, representantes das reflexões sobre as culturas e elementos fundamentais para a compreensão das sociedades e de seus valores. Segundo Bakhtin (1979) é o exterior (a cultura, a sociedade, o mundo) que organiza o interior (os discursos). Dessa perspectiva, as narrativas audiovisuais podem bem ser consideradas como um retrato da sociedade que as produz. A produção audiovisual é também indicativa das referências e de modelos apresentados aos distintos segmentos da população como elementos para identificação ou de diferenciação.

\section{Quem fala?}

É preciso reconhecer que as produções audiovisuais operam a partir de políticas de visibilidade que têm a capacidade de atribuir aos diferentes atores sociais, individuais ou coletivos, valores simbólicos e relevância social que lhes outorgam reconhecimento e legitimidade. $\mathrm{Ou}$ seja, as políticas de visibilidade são, simultaneamente, políticas de invisibilidade, na medida em que os modos de produção, distribuição e circulação de produtos audiovisuais dirigem e educam os olhares para que as escolhas pessoais recaiam sobre determinados tipos de produto, aqueles que fornecem as diretrizes para as identificações e referências, excluindo os demais. As políticas de representação, as formas como determinados segmentos sociais são mostrados na mídia são indicadores relevantes para a compreensão do modo como a sociedade retrata, reconhece ou ignora seus diferentes membros e grupos, em um jogo de poder e de relação visibilidade/
${ }^{1}$ Bourdieu, Pierre. A dominação masculina. Rio de Janeiro: Bertrand Brasil, 1999.

¿É importante ressaltar que a referência a grupos minoritários não se restringe a minorias numéricas, mas abrange também grandes contingentes populacionais que são tratados de maneira discriminatória. 
invisibilidade em que os grupos minoritários $^{2}$ são, com freqüência, sub-representados ou estereotipados.

A partir desses pressupostos, acredita-se que uma das tarefas da crítica cultural e, sobretudo, da crítica midiática, deva ser realmente a de identificar e compreender o funcionamento e as dinâmicas dos processos comunicativos e sua participação na construção de visões de mundo. Suas bem elaboradas articulações de informações, as escolhas apontadas como possíveis e desejáveis, a ênfase a determinados assuntos e a omissão de outros, a escolha de temas e ângulos em que serão mostrados incidem nos processos de atribuição de sentido às coisas, ao mundo e às relações sociais.

Entretanto, ainda que sejam relevantes para a identificação das políticas de representação, entendese que o trabalho analítico não pode se esgotar na crítica da produção cultural hegemônica, especialmente em um momento em que as novas tecnologias - entre elas, as de registro audiovisual, como a digitalização de imagens - são mais acessíveis a uma grande parcela da população do que os métodos convencionais de filmagem e possuem, portanto, um enorme potencial para colocar em cena novos discursos e novas formas de representação das singularidades. Dependendo das formas de distribuição, do alcance e da capacidade de gerar debates, pode operar como um importante processo de dinamização cultural e contribuir para políticas mais democráticas de comunicação e de difusão de informações. Assim, buscar as possibilidades de surgimento de novas e diferentes falas é também tarefa que cabe ao pesquisador.

Dessa perspectiva cabe agora a pergunta: Pode o subalterno (as minorias, os invisíveis) falar?
(SPIVAK, 1999). Esse é o título de uma das mais instigantes reflexões que estão no centro dos debates atuais sobre as possibilidades de emancipação das culturas periféricas/subalternas. Ainda que, segundo a perspectiva de Spivak, não exista possibilidade de crença na representação dos subalternos, mas apenas na ação, pode-se acreditar que a ação aconteça também tramada dentro dos sistemas de signos, por meio do deslocamento dos campos discursivos que colocaria a iniciativa da transformação social nos grupos subalternos e nos discursos por eles produzidos.

É a mudança de perspectiva, a alteração do lugar social da enunciação, que poderá tentar romper a articulação dos discursos midiáticos com as forças hegemônicas, pois é essa articulação que torna viável a legitimação e a validação de uma visão de mundo particular como se fosse universal, naturalizando-a e tornando-a imperceptível: uma visão de mundo que exclui ou condena à invisibilidade os sentidos divergentes, permitindo a incorporação dos saberes e da cultura hegemônica como os saberes e a cultura.

Essa tentativa de identificar novas narrativas e novas possibilidades discursivas passa inevitavelmente pelas formas de reorganização social que estão emergindo após a fragmentação das instituições tradicionais de lutas populares (partidos, associações, sindicatos). A compreensão da efetividade de suas lutas materiais e simbólicas, da busca de legitimidade para as diferenças e/ou para demandas específicas, assim como o alcance social de seus discursos podem ser mais bem compreendidos a partir da competência das práticas comunicativas utilizadas como 
estratégia de construção e afirmação de identidades, de negociação de espaços simbólicos com o conjunto da sociedade e de elaboração de seu projeto histórico. Essas estratégias colocam ao pesquisador questões relacionadas ao refinamento de teorias e metodologias destinadas a compreender e contribuir para o desenvolvimento dos movimentos contra-hegemônicos. Esses novos grupos ou "coletivos" conhecem bem a necessidade de adquirir visibilidade social para legitimarem-se diante de membros de seu próprio grupo ou da sociedade e recorrem, freqüentemente, às estratégias discursivas e às ações demonstrativas como elementos fundamentais.

Visibilidade - desafios para grupos minoritários

De uma perspectiva que privilegia a importância das manifestações originárias dos diferentes grupos sociais, pretendese avaliar o lugar que estas podem ocupar na construção de suas representações e/ou contrarepresentações. Interessa ainda investigar ainda a existência de uma possível dicotomia entre aquilo que é produzido "sobre" determinados grupos e aquilo produzido "por" esses mesmos grupos, bem como os agenciamentos possibilitados por instituições oficiais.

Como forma de aproximar estas construções teóricas dos acontecimentos presentes na vida concreta dos indivíduos será tomado aqui como exemplo o episódio conhecido como "crise de Oka", Canadá, acontecida na cidade do mesmo nome no verão de 1990. A "crise" originalmente teve início com um protesto de um pequeno grupo de Mohawks contra a ampliação de um campo de golfe sobre uma parte considerada sagrada de seu território, local de cerimônias fúnebres. A intervenção da polícia para desbloquear a rodovia de acesso à cidade e a morte de um oficial intensificou o conflito. Para dar suporte a este grupo, o grupo Kahnawake, que vive em uma reserva ao sul de Montreal bloqueou a ponte Mercier em 11 de julho e a manteve fechada até 5 de setembro. Os residentes da parte sul de Montreal hostilizaram os nativos e a força militar foi convocada ${ }^{3}$. As dificuldades de acordo levaram ao enfrentamento e à extensão do conflito. Naquele verão os vários episódios de enfrentamento entre população autóctone, polícia e exército forneceram farto material para que a mídia construísse imagens e representações dos membros dos grupos envolvidos no conflito e revelasse o quanto de fratura social, econômica e cultural existe entre nativos e não-nativos naquela sociedade. Da mesma forma forneceram elementos para a produção de outras narrativas, a partir de outros lugares de enunciação.

No Canadá, um país formado por diversas etnias e que se pretende multicultural, a convivência entre elas não acontece sem conflito, em especial quando as divergências envolvem a propriedade de terras, a diferentes formas de relação com e de apropriação da natureza, bem como as maneiras de conceber o progresso e os avanços tecnológicos. Naquele país, os grupos minoritários têm uma visibilidade peculiar: em uma primeira visada, todos perdem espaço para a dimensão que os grupos étnicos assumem na sociedade. Por ser formada por diferentes etnias, a sociedade canadense, e a quebequense em particular, se defronta com questões relativas à manifestação, expressão e convivência com o diferente, com
${ }^{3}$ Relato retirado de Lorna Roth, Mohawk Airwaves and Cultural Challenges: Some Reflections on the Politics of Recognition and Cultural Appropriation After the Summer of 1990, Canadian Journal of Communication, vol 18, 1993. Não é o caso de estender sobre as origens históricas dos conflitos entre autóctones e camadas hegemônicas no Canadá, mas remontam ao processo de colonização, à disputa por posse de território e aos diferentes acordos realizados entre o grupo dirigente e as nações indígenas. 


\footnotetext{
${ }^{4}$ Recentemente implementou um projeto chamado "studiomobile": um ônibus equipado com um estúdio de gravação que possibilita a jovens de comunidades distantes dos grandes centros realizarem seus próprios filmes (segundo a responsável pelo setor de Operações da ONF, Mme Michelle Beusekom) este ônibus estaria, naquele momento (outubro de 2008), no Brasil.
}

a alteridade. $\mathrm{O}$ grupo de origem francesa, majoritário no Quebec e minoritário em relação ao próprio país, se depara com um movimento migratório intenso e geograficamente variado e, via intervenção estatal, em particular na área da cultura - tenta instaurar políticas destinadas a promover a interculturalidade, ou, de maneira mais simplificada, o intercâmbio e a convivência intercultural. A intervenção estatal se dá em muitas áreas da produção cultural, mas importa aqui apenas o circuito de produção e difusão de audiovisuais. E como a diversidade étnica também é ampla, para efeitos deste trabalho a atenção recai sobre a produção dos povos autóctones (denominação para as nações indígenas remanescentes da colonização anglo-francesa) promovida por órgãos governamentais, como por exemplo o Office National du Filme, instituição que tem uma presença substantiva na área de produção cinematográfica

Criado em 1939 o Office National $d u$ Film, a instituição destina-se a promover - fora do alcance dos padrões estéticos hollywoodianos - a produção cinematográfica canadense. Atualmente são financiados 100 filmes anualmente - 60 em língua inglesa e 40 em língua francesa, a maioria trata-se de documentários ou animações (muito bem estimulada e desenvolvida no Canadá).

Inicialmente concebido para servir os fins propagandistas do governo federal durante a segunda guerra mundial, a ONF diversificou rapidamente suas produções para responder às necessidades dos diversos ministérios do governo de sua clientela, como escolas e, nos anos 1950 e 1960, as redes de televisão. Graças a uma política de produção independente, conseguiu permanecer fora do alcance da indústria cinematográfica hollywoodiana e aos ataques de grupos avessos às empresas produtivas estatais. A fidelidade aos objetivos de pesquisa $\mathrm{e}$ de experimentação só permitiu que privilegiasse produções consideradas marginais no cinemax os documentários e os filmes de animação. Esta fidelidade conquistou personalidades marcantes como McLaren, considerado um dos grandes mestres do cinema de animação. Sem querer entrar na história da ONF, pode-se afirmar que a instituição tem conseguido firmarse como uma escola de cinema que permite a experimentação e a criatividade descomprometida unicamente com o mercado.

Atualmente a ONF possui sete estúdios $^{4}$ de filmagem e produz 100 filmes por ano, a maioria documentários e filmes de animação. Entre estes ocupa espaço importante a produção autóctone cuja distribuição é facilitada pelos canais públicos de televisão e pelo Aborigenal People's TV Network - rede de televisão dos povos autóctones.

Em termos empíricos, para realizar a avaliação das narrativas sobre ou para e distingui-las das narrativas feitas por diferentes grupos se valerá de duas fontes de informação: as formas como a mídia canadense representa grupos minoritários, em particular os autóctones, e em contrapartida, o discurso presente nos quatro filmes documentários sobre o episódio de Oka realizados pela cineasta autóctone Alanis Obomsawin. Esta é uma cineasta representativa reconhecida no meio cultural canadense. Membro da nação Abenaki, é uma das mais reconhecidas e premiadas diretoras canadenses e pode-se considerá-la como uma voz que destoa do conjunto da grande mídia canadense 
e por certo pode ser representante das novas falas, novos olhares e, principalmente, de novos lugares de enunciação. Foram analisados os quatro documentários que compõem o conjunto intitulado $270 \mathrm{Ans}$ de résistance: Kanehsatake: 270 ans de résistance (1993); Je m'appelle Kehentiiosta (1995); Spudwrench, $l$ ' homme de Kanahwake (1997) e Plui de pierres à Whiskey Trench (2000).

A partir de leituras sobre a representação de minorias na grande mídia canadense - com o risco que toda generalização oferece - podese afirmar, considerando que os trabalhos consultados, que existe uma evidente sub-representação ou estereotipia dos diferentes grupos minoritários nos meios de comunicação, dentre eles os membros da população autóctone, grupo que nos interessa aqui. A jornalista Loreen Pindera ${ }^{5}$, em entrevista televisiva afirma que a grande mídia ainda representa o status quo, o homem branco, classe média do Canadá. O que estiver fora dessa classificação aparece como "outro". Segundo Mahtan ${ }^{6}$, a representação dos autóctones continua a perpetuar os estereótipos, classificando-os em categorias que vão do "bom selvagem" ao "bárbaro sanguinário" ou "índio alcoólatra". Sobre o episódio de Oka, especificamente, o Canadian Journal of Communication ${ }^{7}$, em sua décima oitava edição (em 1993), publicou um número temático com várias análises referentes ao conflito. O editorial, escrito por Gail Valaskakis $^{8}$, a propósito da representação dominante construída pela mídia sobre a chamada "crise de Oka" e dos índios Mohawk que ocuparam a rodovia que dá acesso à cidade de Oka, aponta a construção de uma representação enviesada dos nativos. Valaskakis afirma que a mídia criou uma nova figura: o "guerreiro" (warrior), representado de uma perspectiva essencialista, monolítica e criminalizada. No estudo Echoes of a Proud Nation: Reading Kahnawake's Powwow as a Post-Oka Text, de Valda Blundell ${ }^{9}$, a autora afirma que a mídia relatou que, para os oficiais presentes os "guerreiros" eram "criminosos", "terroristas" enquanto que para os Mohawks "guerreiro" (warrior) significa "aquele que leva a incumbência da paz". No artigo intitulado The mohawk warrior: Reappropriating the stereotype ${ }^{10}$, a autora Heather Smyth informa que nas manchetes dos jornais os "warriors" apareciam como terroristas, guerrilheiros, mafiosos e comparações com Belfast, Beirute com outras situações de guerra não eram incomuns. A associação entre os Mohawks e o tráfico de drogas, armas e jogos ilícitos também era comum. Segundo a autora essa imagem construída pela mídia tinha o interesse de desviar a atenção para cigarros e armas (contrabando) ao invés de focar o assunto real: um conflito por disputa de terra e soberania. Além de descontextualizar a luta desses grupos nativos pela posse da terra essa abordagem justificava o uso da força contra eles.

A visão dos nativos é bem outra. Para eles tratava-se da questão de defender a sua terra contra invasores, o que revela que as comunidades autóctones são levadas a outros campos de batalha, dessa vez para a produção de contranarrativas que mostrem construções identitárias em que não sejam posicionados como o Outro do nãoíndio, suas próprias representações do passado de forma a permitir a elaboração de projetos futuros diferentes dos que lhes são designados pela camada hegemônica.
${ }^{5}$ www.media-awareness.ca. Acessado em 16/10/2008.

${ }^{6}$ MAHTANI, Minelle. La représentations dêsminonités:les médias canadiens et l'identité des grupes minoritaires. www. metropolis.net. Acessado em 16/10/ 2008.

${ }^{7}$ Além dos trabalhos aqui citados existe um interessante estudo sobre o papel do rádio durante o conflito. Ver, a respeito, o artigo intitulado Mohawk Airwaves and Cultural Challenges: Some Reflections on the Politics of Recognition and Cultural Appropriation After the Summer of 1990, escrito por Lorna Roth.

${ }^{8}$ VALASKAKIS, Gail. Parallel Voices: Indians and Others - Narratives of Cultural Struggle. Canadian Journal of Communication, vol.19, n. 3, 1993. www.cjc-online.ca. Acessado em $7 / 11 / 2008$.

${ }^{9}$ www.cjc-online.ca . Acessado em $7 / 11 / 2008$

10 SMYTH, H. Canadian Journal of Cultural Studies, Topia, Number 3, Spring, 2000. http:// pi.library. yorku.ca. Acessado em 20/10/ 2008. 
A vez do Outro ou a Voz autóctone

Ainda que as produções audiovisuais ofereçam amplas possibilidades para sua melhor compreensão, como as análises das imagens em toda sua variedade de cores, tomadas, encenações, gestualidades e muitos outros elementos constitutivos do produto audiovisual, neste trabalho o foco recairá prioritariamente sobre as narrativas - os discursos - e sobre a utilização da voz em produções feitas pelas próprias comunidades ou por indivíduos fortemente identificados com elas. Diz-se o foco prioritário porque a idéia inicial de se analisar apenas as narrativas seria mutilante para os filmes de Obomsawin, dada a eloqüência de suas imagens. Assim, algumas imagens se impuseram ao pesquisador.

Para analisar os documentários referidos valeu-se, em um primeiro momento, das contribuições de Bakhtin (1979) e também das transposições que Robert Stam fez daquele autor para as análises das linguagens cinematográficas no intuito de compreender as relações entre linguagem e poder, relações que se encontram também nas filmografias. Nesses termos, vale perguntar-se qual seria a posição social que ocupam os falantes nos filmes, de quem são as vozes, em especial no que diz respeito às possibilidades narrativas e de expressão e reconhecimento de elementos emocionais e afetivos, a entonação. Ainda segundo Stam (2000, p. 64) "o narrador torna-se a voz do conhecimento generalizante enquanto os narrados são a voz da experiência que não discrimina. $\mathrm{O}$ narrador traduz as palavras alheias para a linguagem impessoal da verdade objetiva Os"narrados" fornecem provas para as generalizações do narrador; na confusão de suas palavras encontrase a chave para o sentimento profundo de seu discurso que, no caso de Obomsawin é um discurso altamente identificado com o discurso narrado. Além de ser autóctone a cineasta passou os 78 dias de barricada filmando lado a lado com os Mohawks ${ }^{11}$.

Sua câmera vê e ouve as narrativas de um povo tal como ele se coloca diante dela, contando suas histórias, suas memórias, suas crenças, desafios, projetos e esperanças. Sobretudo sua memória. $\mathrm{Na}$ tetralogia "270 anos de resistência a memória" se concentra na recuperação e registro dos conflitos conhecidos como a "crise de Oka".

O primeiro, Kanehsatake (1993), mostra o início do conflito e a vida diária do grupo detrás das barricadas erguidas sobre a rodovia que leva a Oka. Em um tom absolutamente calmo uma voz serena começa seu relato situando historicamente o contexto da luta: as sucessivas desapropriações, a luta pela preservação da terra, dos costumes, da memória. A memória pessoal e coletiva são convocadas, em diversas entrevistas, para compor um discurso que dê ao conflito um significado para além do factual, que gira em torno da expansão de um campo de golfe. Nas lentes de Obomsawin esse campo de golfe é apenas mais um episódio em uma longa história de colonização, de recuo, de perda.

O segundo filme intitula-se $J e$ m'appelle Kahentiiosta (1995) e prima por fazer uma narrativa em contraponto. Não há como não usar um certo olhar estruturalista na análise desse conjunto de obras e neste filme, especificamente, explicita-se ao espectador as oposições entre nativos e não- 
nativos, entre presente e passado, entre natureza e progresso enfim, entre valores e maneiras de ver o mundo que se opõem na sociedade. Nas cenas de prisão ficam evidentes os compromissos solidários entre os membros da comunidade que são presos por recusar a fornecer à justiça um nome "canadense". Em diversas cenas de prisão de manifestantes, o fundo musical de flauta indígena opera dialeticamente entre duas realidades: a que é e a que deixou de ser e que pode vir a ser. Neste filme, o que parece uma narração em off é o depoimento, sobretudo de mulheres, sempre com um tom de voz extremamente sereno, relatando fatos passados que recuperam e registram, de forma sutil, a história e os acontecimentos relevantes para os povos autóctones, suas lutas, suas vitórias e suas perdas.

E a perfeita consciência de que a terra lhes pertence há séculos, daí a justificativa do embate atual. A câmera de Obomsawin é uma câmera comprometida, ela não se esconde atrás de nenhuma pretensão de "objetividade": ao contrário, parece ser propositadamente subjetiva, partidária. Mostra a vida atrás das barricadas, a retirada de pessoas - mulheres e crianças - de suas casas, o papel da imprensa cenas de repórteres, fotos de manchetes de jornais, a presença de fotógrafos, Entretanto, possui o distanciamento necessário para contextualizar os fatos e para entrevistar, tempos depois pessoas que participaram do conflito, ouvir suas memórias.

Depois desse vem Spudwrench - l'homme de Kahnawake (1997) em que a narrativa reconstrói a trajetória de vários homens que trabalharam com a indústria do aço e foram responsáveis pela edificação de várias pontes e edifícios no
Canadá e nos Estados Unidos. É um retrato de Randy Horne e das gerações de Mohawks que o precederam como trabalhadores da construção e um olhar único sobre um homem que, atrás das barricadas, defende com paixão o seu território considerado sagrado. A utilização da história de vida de trabalhadores da construção e sua audácia e coragem ao trabalhar em condições arriscadíssimas é uma forma de transferir as qualidades dos trabalhadores para os "warriors". Também neste filme a cineasta demonstra saber realmente o valor das imagens na construção de representações sociais, pois existem várias cenas em que o foco recai sobre repórteres, fotógrafos e outros profissionais da mídia.

As oposições imagéticas também são recorrentes nesse filme. A cena de um navio passando quase que no quintal de uma casa de nativos, a estabilidade dos relacionamentos e dos casamentos, a proximidade entre as comunidades, a preocupação em "manter as crianças fora da rua" são temas constantes nesse documentário e revela que a oposição nativo/nãonativo pode ser uma aliada valiosa ao construir representações, uma vez que sugere a superioridade dos valores Mohwaks: a forte conexão com a terra e as lutas para defendêla, a relação amigável e respeitosa com a natureza, o valor da memória, o apego e o apreço ao lugar, às tradições e à cultura se opõem aos valores mercantilistas da sociedade canadense.

Por fim, Pluie de pierres à whiskey Trench (2000) relata a ocupação solidária da ponte Mercier, ao sul de Montreal, por membros da comunidade Kahnawake em solidariedade aos manifestantes de Oka. O filme inicia, como os demais, com a narrativa de uma mulher que 
chora ao lembrar-se dos fatos, em closes sobre rostos femininos e infantis que relembram sua participação no episódio. Este é um filme que tem a memória como elemento central e tempo como recurso técnico para construir uma imagem dos Mohawks. Da memória da participação das mulheres na ocupação da ponte salta no tempo e recupera imagens de mapas do território indígena antes da terra ser tomada pelos invasores, a diminuição progressiva do seu patrimônio, os acordos rompidos, a participação deles na construção da ponte, os sucessivos desalojamentos desde 1936 enfim, coloca em cena a "história dos vencidos". Na volta ao tempo presente, os depoimentos atuais - sempre em um tom de voz suave e sereno, que procura esconder toda emoção, muitas das depoentes choram ao longo da rememoração dos fatos vividos - são intercalados com cenas da atuação da polícia, de tanques do exército e dos moradores da cidade que, em gestos de extrema violência apenas observada pelos policiais, apedrejam os carros que abandonam a ponte depois de terminado o conflito. Os nativos, ao sair da ponte em seus carros, passam por uma espécie de "corredor polonês" formado por moradores que lhes atiram pedras em sinal de desaprovação da ocupação $\mathrm{da}$ ponte.Aliadas às cenas de fotografias de manchetes de jornais, o documentário impõe a percepção de uma sociedade fragmentada, cindida, e contra os índios. O apedrejamento acontece aos gritos de "let them die" (deixe-os morrer).

O que se percebe, nos filmes de Obomsawin, é que a narração vem do próprio "narrado". Inicialmente percebida como voz off de um narrador, depois de decorridos alguns minutos de filmagem, percebe-se que a voz do narrador é a voz de um entrevistado que assume a narração de parte da história. Pode-se dizer história porque nos filmes de Obomsawin analisados, trata-se sobretudo, do registro e da recuperação da história, de fatos históricos que aconteceram no início da década de 1990 e que, para além de sua visibilidade midiática informativa, receberam o tratamento de memória dos vencidos, memória de um povo que nem sempre pode oferecer ao seus conterrâneos a sua própria versão dos fatos. Uma visão que percebe o desencadear do conflito tendo como parâmetro de avaliação outros valores, outra noção do bom e do desejável. Sem tentar realizar aqui uma análise estruturalista da produção de Obomsawin - mesmo porque o objetivo não é realizar análise fílmica, mas avaliar como acontece a utilização de filmes para a construção de representações sociais - podemos afirmar que são recorrentes as oposições e mesmo contradições entre aquilo que é relevante para a cultura autóctone em contraposição à cultura "progressista" do segmento dominante da população. Estão claras as oposições entre civilização e cultura, entre valores relacionados à memória e ao culto dos ancestrais, à preservação e fruição da natureza e dos recursos naturais em contraste com a dominação e o uso dos recursos naturais para a ampliação do "desenvolvimento". São também freqüentes as cenas em que se mostra um navio passando por um canal construído quase que no quintal das casas, enquanto as imagens dos autóctones são tomadas em um contato "amigável" com a natureza. A relação com a terra, com a água, com a vegetação - a "força" que as árvores transmitem, por exemplo são mostradas de dois pontos de vista contrários: de exploração, de um lado; e de proximidade, de outro. 
Nas narrativas de Obomsawin, percebe-se que a voz, no sentido em que a compreende Bill Nichols (2004), é efetivamente, "aquilo que, no texto, nos transmite o ponto de vista social, a maneira como ele nos fala ou como organiza o material que nos apresenta"... e que terminam por se constituir em "estratégias organizacionais (que) estabelecem uma leitura preferencial" .

Nestes filmes acontece também aquilo que Bakhtin chama de "solidariedade total entre autor e herói nos limites de um contexto retoricamente construído, no que concerne às apreciações e entoações, a retórica do autor e a do herói podem eventualmente se sobrepor uma à outra; suas vozes, então, fundem-se e criam-se longos períodos que pertencem simultaneamente à narrativa do autor e ao discurso interior (por vezes mesmo exterior) do herói. (Bakhtin: 1979, p. 157). Essa solidariedade, este falar desde dentro da comunidade coloca o discurso de Obomsawin como o próprio discurso autóctone. Um dos possíveis discursos das comunidades autóctones, pois generalizar, neste caso, seria o mesmo que sugerir a existência de um único discurso autóctone, seria sugerir a unificação e coesão de algo que é, também, diverso e muitas vezes divergente.

Mídia, representação, cultura: reflexões

A realização desta investigação sobre a produção midiática canadense durante o período conhecido como "crise de Oka" serviu para provocar a reflexão sobre alguns fenômenos que devem ser mais bem compreendidos, entre eles o papel crucial que cabe às formações culturais nas estratégias de visibilidade, nos jogos políticos e nos jogos de poder.
Claro está que a luta social tem como esfera privilegiada o campo da produção e circulação de produtos culturais. As informações colhidas revelam que, apesar das políticas estatais que promovem o multiculturalismo - em nível estatal e o interculturalismo - em nível provincial - as resistências às diferenças estão presentes nas representações que são construídas a respeito dos autóctones e dos Mohawks, em particular. Existem, no Canadá, instituições destinadas a facilitar a produção e a reprodução da voz dos subalternos ${ }^{12}$, entre elas as rádios comunitárias e a ONF. A circulação dessas vozes dissonantes na sociedade canadense leva a crer que as produções audiovisuais possuem, mesmo que seja em pequena escala, dado o alcance de cada mídia, uma capacidade de provocar discussões em torno de determinados temas favorecendo os processos de dinamização cultural ${ }^{13}$ entendidos como a capacidade que os diferentes meios de comunicação possuem de fazer circular discursos e de provocar reflexões sobre determinados temas, bem como das maneiras diferenciais como os indivíduos e grupos se apropriam dessas informações e os sentidos que elaboram a partir delas.

Arlindo Machado, ao considerar suas características técnicas particulares, sua capacidade de despertar atenção, interesse e de reavivar a memória, chega a afirmar que as produções audiovisuais podem ser consideradas como um "convite à mobilização ${ }^{14 "}$. Mobilização essa que pode vir a ser um marco e/ou uma referência histórica sobre a convivência entre comunidades em um mesmo território. Ou servem para desmontar uma versão histórica de coesão social e deixar claro, para o conjunto da sociedade as diferenças e as desigualdades. Em
12 É necessário precisar o que se entende aqui por subalterno: tratase, aqui, dos segmentos da sociedade que se inserem de uma forma subordinada tanto nas relações produtivas como nas relações sociais, nas quais a desigualdade é de ordem material e simbólica.

${ }^{13} 0$ conceito de dinamização cultural vem sendo desenvolvido por pesquisadores do MIGRACOM, grupo de pesquisa sobre migrações da Faculdade de Ciências da Comunicação da Universidade Autônoma de Barcelona onde realizei estágio de pósdoutoramento em 2007.

\footnotetext{
${ }^{14}$ Machado, Arlindo. Máquina e imaginário. S. Paulo: EDUSP, 2001, p.25.
} 
algumas cenas de Obomsawin vêem-se entrevistados reagindo assombrados diante dos fatos violentos e perguntando (e se perguntando): Mas, o que é isso? Estamos no Canadá! Ou seja? Onde está o país pacífico que aprendemos na escola e na mídia? Onde está o país unificado e multicultural?

Quando as produções culturais contra-hegemônicas conseguem provocar tais reações e tais reflexões nos indivíduos comuns, pode-se que dizer que o subalterno sim, pode falar. Entretanto, resta ainda uma grande dificuldade. Falar para quem? quem ouve? No caso do cinema, como na maioria dos outros suportes midiáticos, o público está pouco habituado a essas vozes dissonantes. Por essa razão, não são muitos os espaços de circulação dessas produções. O que tem se revelado promissor, no caso da produção audiovisual, é o aumento da quantidade e qualidade de festivais e mostras audiovisuais. Elas têm operado em pelo menos duas instâncias complementares: a que tem seu maior relevo no espetacular do evento e como unidades de significação. Como eventos espetaculares são capazes de provocar amplas coberturas de mídia e, portanto, de ser recebidos e apreciados por um público bastante amplo. Mas, contraditoriamente, esse caráter espetacular que quase sempre as produções audiovisuais assumem, a profusão de imagens que velozmente transitam no circuito cultural durante sua realização, também aceleram os processos de esquecimento e banalização, enfraquecendo todo o poder de sedimentação de poderiam conter. No entanto, a eficácia dessas produções transita por estratégias de apropriação e (re)trabalho dos conteúdos que vem a ser um processo de dinamização cultural promovido por práticas comunicacionais produtivas, de reflexão sobre os produtos cinematográficos que não se rendem à sua capacidade de envolvimento $\mathrm{e}$ de sedução.

Como unidades de significação podem se converter em mapas de sentidos, oferecendo oportunidades de reflexão e de questionamento a platéias que incorporam essas narrativas em seus discursos (seja assimilando, negando ou ressignificando-as) no sentido de fortalecer e legitimar singularidades perante si mesmos e perante o conjunto da sociedade.

Por fim, mas não menos importante, tornam-se mapas culturais, caminhos para que os atores coletivos possam se movimentar, se comunicar uns com os outros, compartilhar experiências e articular lutas por meio da publicização de suas narrativas e de seus discursos, compreendidos não apenas em sua capacidade de construir identidades como também de legitimar as singularidades dentro do próprio grupo e perante a sociedade. É uma das maneiras de fomentar um debate e colocar em xeque as políticas de identidade e de reconhecimento que acabam por ocultar muitas vezes as origens históricas e econômicas das desigualdades e, num ato de "tolerância", destine ao Outro um lugar social previamente determinado.

\section{Abstract}

This text is part of a research that aims to contribute to better understand the role of cultural diversity and difference in the media productions may offer to the process of cultural enrichment and to the democratization of the social relations. We believe that in the contemporary societies, where the logic of the spectacle spreads out to the social relations, media visibility may produce relevant forms of recognition and legitimacy of the 
differences.

Key-words: diversity, representation, audiovisual, Canadá.

\section{Referência}

BAKHTIN, M. Marxismo e filosofia da linguagem. São Paulo: Hucitec, 1979.

HALL, S. The centrality of culture: notes on the cultural revolutions of our time. In: Thompson, K. Media anda cultural regulation. London: Sage publications, 1997.

LORITE, N. G. Tratamiento informativo de la inmigración en España: 2002. Barcelona, INMERSO, 2003.

MAHTANI, Minelle. La représentation des minorités: les médias canadiens et identité des groupes minoritaires. in : www.metropolis.net.

MARTINEZ, A. Democracia audiovisual: uma proposta de articulação regional para o desenvolvimento. São Paulo: escrituras ed., 2005.

PAIVA, R. e Barbalho, A. Comunicação e cultura das minorias. São Paulo: Paulus, 2005.

ROTH, L. Mohawk Airwaves and Cultural Challenges: Some Reflections on the Politics of Recognition and
Cultural Appropriation After the Summer of 1990. Canadian Journal of Communication, vol. 18, n. 3, 1993.

SANTAOLALLA, I. Los "otros": etnicidad y 'raza' en el cine español contemporáneo. Zaragoza: prensas universitarias de Zaragoza, 2005.

SMYTH, H. The Mohawk warrior: reappropriating the colonial stereotype. Canadian Journal of Cultural Studies, Topia, Number 3, Spring, 2000.

STAM, R. e Shohat Ella. Multiculturalismo, cine y medios de comunicación. Barcelona, Paidós, 2002.

THOMPSON, K. Media and cultural regulation. London: Sage publications, 1997.

TORO, J. B.. A construção do público: cidadania, democracia e participação. Rio de Janeiro: SENAC, 2005.

VALASKAKIS, G. Parallel Voices: Indians and Others: Narratives of Cultural Struggle. Canadian Journal of Communication, vol.18, n. 3, 1993.

Web sites www.cjc-online.ca. www.media-awareness.ca. www.metropolis.net. 